\title{
Preface: Recent advances in tropical lake research
}

\author{
Alonso Ramírez • Margarita Caballero • Gabriela Vázquez • Checo Colón-Gaud
}

Accepted: 14 October 2020/Published online: 3 November 2020

(C) Springer Nature Switzerland AG 2020

Studies on tropical lakes have provided valuable information for advancing our understanding of limnology and lake ecology in general. Although we have been able to accumulate large amount of research on tropical lakes and ponds, our overall understanding remains limited when compared to temperate region counterparts (Lewis, 2000). The lack of a solid understanding of tropical lake processes (biology, seasonality, water quality) hinders our ability to manage and conserve lake ecosystems. In limnology, it is frequently not possible or advisable to try to

Guest editors: Alonso Ramírez, Checo Colon-Gaud, Margarita Caballero \& Gabriela Vázquez / Recent Advances in Tropical Lake Research

A. Ramírez $(\bowtie)$

Department of Applied Ecology, North Carolina State University, Raleigh, NC 27695, USA

e-mail: alonso.ramirez@ncsu.edu

M. Caballero

Laboratorio de Paleolimnología, Instituto de Geofísica, Universidad Nacional Autónoma de México, Coyoacán, 04510 México, D.F., México

\section{G. Vázquez}

Instituto de Ecología A.C., Carretera Antigua a Coatepec No. 351, El Haya, 91073 Xalapa, Veracruz, México

C. Colón-Gaud

Department of Biology, Georgia Southern University, P.O. Box 8008, Statesboro, GA 30460-8008, USA transfer knowledge from higher to lower latitudes, thus the importance of encouraging more investigation in tropical lakes.

This special section highlights ongoing work in different parts of the tropics, with particular emphasis on the Neotropics. This series of manuscripts comes from an open invitation to authors working on tropical lakes and ponds, the goal is to showcase the diversity of ongoing work and their contribution to our understanding of lake ecology and limnology in general. Studies cover different topics, ranging from trophic interactions, lake dynamics, and historical perspectives on the study of lakes.

Our opening paper by Mayer (2020) details the interactions between fish, algae, and physical factors in a shallow tropical pond, in Hawaii. Omnivorous fish are common in tropical ponds and lakes, where they impact more than one trophic level. In tropical lakes, omnivorous fishes consume both phytoplankton and zooplankton, thus having a top down control on both trophic levels. Mayer studied how the disappearance of tilapia from a Hawaiian pond resulted in changes in multiple components of the ecosystem, including nutrients, suspended sediment, organic matter, and algal biomass. This study advances our understanding of the role of omnivorous consumers on tropical lakes.

Caballero and Vázquez (2020) discuss mixing patterns and deep chlorophyll $a$ maxima (DCM) in a eutrophic tropical lake in western Mexico. Our understanding of DCM dynamics in tropical lakes is 
limited, with most studies focusing on oligotrophic temperate lakes. Their study is among the first to describe these phenomena in the tropics. They report the formation of DCM as a recurrent feature in this lake, developing during the stratification period at the top of the hypolimnion, associated to a high light penetration and epilimnetic $\mathrm{P}$ depletion. The study reports an increase in hypolimnetic temperature of $\sim 1^{\circ} \mathrm{C}$ over time. Climatic patterns (e.g., El Niño) are likely drivers of lake and DCM dynamics. This study is the first report of recurrent DCM formation in the northern limit of the Neotropics.

Our understanding of the long-term dynamics of tropical lakes is limited. Umaña-Villalobos \& AvilésVargas (2020) discuss the findings of a long-term study of plankton dynamics in Lake Cote, Costa Rica. They assessed planktonic communities and their variations over time from 2002 to 2018. The lake outflow is used as source of water for hydroelectric power generation since 2003 . The species composition was characteristic of a meso to eutrophic lake, and they detected changes in the dominance of the species. Plankton dynamics appears to be the result of outflow management for power generation and global climate change.

The last contribution to our series is a historical analysis of limnology in Ecuador, a country with a long tradition in lake studies. Steinitz-Kannan et al. (2020) describe the history of limnology in Ecuador, starting with studies in the 1700 s that described freshwater resources of the region. As with other areas of study in Latin America, limnological research started as a field dominated by researchers from outside the country. However, today there is a more active participation from local scientists, and Ecuadorian universities are playing an important role advancing our understanding of freshwater ecosystems in the country.

Overall, our series on tropical lakes provides examples of the diversity of ongoing research in the region, in particular the Neotropics. Studies highlight the unique dynamics of these ecosystems, which present elements that are not common in temperate region lakes (e.g., dominance by omnivorous fishes). The impacts of climate change on lake dynamics were also documented in some of the studies. Overall, all studies stressed the urgency of understanding lake dynamics with a tropical context, rather than applying concepts developed in temperate regions. Tropical lake management and conservation will benefit greatly from a better understanding of tropical limnology.

We appreciate support provided by the journal editors and their staff during the processing and evaluation of this special section. All guest editors assisted in the handling of manuscripts, selection of reviewer, and handing of comments. However, journal editors were responsible for the oversight and for final decisions on each work. We thank all reviewers for their excellent and thoughtful work. Reviews are time consuming, but critical for maintaining the quality and integrity of scientific research. We hope this group of papers aid in advancing our understanding of lake ecosystems in tropical latitudes and lakes in general.

\section{References}

Caballero, M. \& G. Vázquez, 2020. Mixing patterns and deep chlorophyll $a$ maxima in an eutrophic tropical lake in western Mexico. Hydrobiologia, this issue. https://doi.org/ 10.1007/s10750-020-04367-y.

Lewis, W. M., 2000. Basis for the protection and management of tropical lakes. Lakes \& Reservoirs: Research and Management 5: 35-48.

Mayer, T., 2020. Interactions of fish, algae, and abiotic factors in a shallow, tropical pond. Hydrobiologia, this issue. https:// doi.org/10.1007/s10750-020-04375-y.

Steinitz-Kannan, M., C. López, D. Jacobsen \& M. L. Guerra, 2020. History of limnology in Ecuador: a foundation for a growing field in the country. Hydrobiologia, this issue. https://doi.org/10.1007/s10750-020-04291-1.

Umaña-Villalobos, G. \& L. Avilés-Vargas, 2020. Plankton variations in Lake Cote, Costa Rica, from 2002 to 2018. Hydrobiologia, this issue. https://doi.org/10.1007/s10750020-04387-8.

Publisher's Note Springer Nature remains neutral with regard to jurisdictional claims in published maps and institutional affiliations. 